\title{
ON THE NEGLIGENT USE OF QUANTUM CHEMISTRY CALCULATIONS
}

\author{
MARCIN HOFFMANN ${ }^{1}$ AND JACEK RYCHLEWSKI ${ }^{1,2}$ \\ ${ }^{1}$ Quantum Chemistry Group, Faculty of Chemistiy, Adam Mickiewicz University \\ Grunwaldzka 6, 60-780 Poznań, Poland \\ ${ }^{2}$ Institute for Bioorganic Chemistiy, Polish Academy of Sciences \\ Noskowskiego 12/14, 61-704 Poznań, Poland \\ (Received 15 July, 2001)
}

Quantum chemical methods have already proven to be very useful in determining molecular structure as well as- in elucidating electronic structure and reactivity also in the context of rational drug design [1]. Thus, it has become the common practice to carry out quantum mechanical calculations. In a recent study on the drug delivery system of chromo-protein antitumor antibiotic C-1027 Okuno et al. performed high resolution NMR experiments, and also carried out density functional theory (DFT) and ab initio calculations [2],

The C-1027 is a chromo-protein consisted of an apo-protein containing 110 amino acids and a labile enediyne chromophore. The reactive, enediyne, is released from the apo- protein, and then it comes into contact with the target DNA, where after the autoaromatization (Bergman) reaction leading to a reactive ( $p$-benzyne type) biradical, it is capable to abstract two hydrogen atoms from deoxyribose of DNA thus destroying the nucleic acid and causing the death of a living eel [ $1 \mathrm{a}, 2]$.

Based on the experimental result Okuno et al. showed that the enediyne moiety is well protected in the apo-protein and well separated from a hydrogen source in the pocket of the protein. When it is released from the apo-protein the enediyne chromophore undergoes conformational change, and exposes its enediyne moiety to the DNA minor groove [2], In this point, they seemed to decide to make their study more persuasive and attractive, so they performed some quantum mechanical calculations. They clearly aimed at proving the con-elation between the reactivity and conformation of enediyne moiety in the apo-protein and in contact with the DNA. Thus, they used the usual quantum mechanical program Gaussian94 [3].

However, they seemed to lack the deeper understanding of the quantum chemical results, which were obtained with this program. Some indications of this could be found in the method section Ab Initio Calculations and Singlet-Triplet Splitting, where they wrote: „We used the biradical aromatic ring systems consisting of the optimized p-benzyne type biradical and benzene, which were superimposed with biradical and chlorophenol rings of C1027-Chr in two (DNA and Apo) states. Optimized geometries of benzene and a p-benzyne type biradical were obtained from density functional theory using BPW91. Zero-point vibrational energies for each system were computed from the scaling factor (0.993). Singlet-point energy calculations $\left(\mathrm{E}_{\mathrm{tot}}\right)$ were also carried out with BPW91/cc-pVTZ and CCSD(T)/cc-pVTZ". Thus, they did not describe precisely what kind of systems they exactly studied, as they did not explain what „superimposed with" 
really means. (It should be noted that presumably to the misprint there is a phrase "singlet point energy" instead of "single point energy").

No more helpful was the note No 23 in Okuno's article where we read [2]: "We used the benzyne ring as a group adjacent to $p$-benzyne biradical for the purpose of the simplicity of ab initio calculation. If chlorophenol ring is employed instead of benzene ring, the functional substituent groups (chloro- and hydroxyl-group) may influence the magnitude of S-T splitting difference for the two C-1027-Chr form. Therefore, the calculated S-T gap difference $(\sim 0.04)$ can indicate qualitative tendency of the $\mathrm{C}-1027$ reactivity. More accurate calculations will lead to these quantitative interpretations." Also supporting information did not provide any clues on quantum mechanical calculations.

However, the worst was to come in the "Results and Discussion" section. In their Table 3, Okuno et al. presented the "computed total energies, zero-point energies, and S-T splittings for biradical aromatic ring systems" in apo-protein and DNA. For the results of Okuno et al. as well as the corrected ones please refer to Table 1 .

Table 1. The results of ab initio and DFT calculations of Okuno et al. as well as the corrected (for the conversion of units) values

\begin{tabular}{l|c|c|c}
\hline & $\begin{array}{c}\text { CCSD(T)/pVTZ } \\
{[\text { Hartree] }}\end{array}$ & $\begin{array}{c}\text { BPW91/pVTZ } \\
{[\text { Hartree] }}\end{array}$ & $\begin{array}{c}\text { ZPE } \\
{[\mathrm{kcal} / \mathrm{mol}]}\end{array}$ \\
\hline Triplet & in apo-protein & & \\
Singlet & -460.2375522 & -463.2012796 & 107.0864691 \\
S-T splitting in Okuno at al. & -460.1084965 & -463.1971597 & 105.7723144 \\
S-T splitting corrected & $1.1850990[\mathrm{kcal} / \mathrm{mol}]$ & $1.3100348[\mathrm{kcal} / \mathrm{mol}]$ & \\
& $-79.669[\mathrm{kcal} / \mathrm{mol}]$ & $-1.271[\mathrm{kcal} / \mathrm{mol}]$ & \\
Triplet & in DNA & & \\
Singlet & -460.2296099 & -463.1959909 & 107.3332236 \\
S-T splitting in Okuno at al. & -460.0998565 & -463.1911972 & 106.0589484 \\
S-T splitting corrected & $1.1445218[\mathrm{kcal} / \mathrm{mol}]$ & $1.2694815[\mathrm{kcal} / \mathrm{mol}]$ & \\
\hline
\end{tabular}

Although they noted that total energies are in au, whereas zero-point vibrational energies in $\mathrm{kcal} / \mathrm{mol}$ they did not convert the units before addition. For CCSD(T)/cc-pVTZ calculations they obtained absolute energies of-460.2375522 and -460.1084965 Hartree for triplet and singlet states in the apo-protein, respectively, with the corresponding zero point vibrational energies of 107.0864691 and $105.7723144 \mathrm{kcal} / \mathrm{mol}$. According to their calculations the energy of singlettriplet splitting equaled:

$(-460.2375522+107.0864691)-(-460.1084965+105.7723144)=1.1850990 \mathrm{kcal} / \mathrm{mol}$.

Providing they have converted Hartree into $\mathrm{kcal} / \mathrm{mol}$ they would obtain singlet-triplet energy splitting:

$(-460.2375522+460.1084965) \times 627.5095+(107.0864691-105.7723144) \cong-79.669 \mathrm{kcal} / \mathrm{mol}$. 
This means not only the different value but also the completely different value of the opposite sign (!) In the case of triplet and singlet states in DNA in CCSD(T) calculations they obtained triplet energy splitting $=1.2694815 \mathrm{kcal} / \mathrm{mol}$. If they converted units they would result in about $-80.147 \mathrm{kcal} / \mathrm{mol}$. In the case of density functional theory BPW91 calculations the corrected results for the singlet - triplet splitting should be -1.271 and $-1.734 \mathrm{kcal} / \mathrm{mol}$ for the state in apoprotein and in DNA, respectively, instead of 1.310 and $1.269 \mathrm{kcal} / \mathrm{mol}$ obtained by Okuno et al. These findings mean that singlet state was not energetically favored over triplet one in Okuno's calculations as it should be [4], Thus, Okuno et al. obtained wrong energies of singlet-triplet splitting and drawn false conclusions (though these false conclusions were in line with experimental findings).

In a very recent publications [5], Jones and Warner pointed out that the calculated by Okuno et al. [2] small change in singlet- triplet energy splitting for the $p$-benzyne from the antitumor antibiotic C-1027 upon going from non-reactive (apo-protein) to reactive (DNA) environment cannot account for the drug's switch from stability to reactivity [5]. Although Jones and Warner realized that conclusions of Okuno et al. based on computational results are rather strange, they (Jones and Warner) did not find out that the reason for this is caused by a heedless use of quantum chemical calculations.

Because we do not even know what system was actually under computational study we can not say anything of the source of discrepancy between the experiment and the outcome of the calculations of Okuno et al. All in all we think that the example described here should worn against negligent use of quantum chemical calculations.

\section{Acknowledgment}

The authors gratefully acknowledge the financial support from the Polish Committee for Scientific Research (KBN) grant T09A 171 18, and thank Poznan Supercomputing and Networking Center for the access to computer resources therein. M. H. thanks the Foundation for Polish Science for a fellowship.

\section{References}

[1] For example see: (a) Kraka E., Cremer D. J. Am. Chem. Soc. 2000, 122, 8245-8264; (b) Hoffmann M, Rychlewski J. J. Am. Chem. Soc. 2001, 123, 6404-6409.

[2] Okuno Y., Iwashita T. Sugiura Y. J. Am. Chem. Soc. 2000, 122, 6848-6854.

[3] Frisch M. A., Trucks G. W., Schlegel H. B., Gill P. M. W., Johnson B. G., Robb M. A., Cheeseman J. R., Keith T., Petersson G.A., Montgomery J. A., Raghavachari K., Al.-Laham M. A., Zakrzewski V. G., Oritz J. V., Foresman J. B., Cioslowski J., Stefanov B. B., Nanayakkaia A., Challacombe M., Peng C. Y., Ayala P. Y., Chen W., Wong M. W., Andres J. L., Replogle E. S., Gomperts R., Martin R. L., Fox. D. J., Binkley J. S., Defrees D. J., Baker J., Stewart J. P., Head-Gordon M., Gonzalez C., Pople J. A. Gaussian 94, Gaussian Inc.: Pittsburgh, PA, 1995.

[4] Logan C. F., Chen, P. J. Am. Chem. Soc. 1996, 118, 2113-2114.

[5] Jones G. B, Wamer P. M. J. Am. Chem. Soc. 2001, 123, 2134-2145. 